\title{
Working Locally and Globally for Lasting Change: Linking Community Demand and Political Leadership
}

\author{
Barbara Frost
}

\begin{abstract}
1 Introduction
WaterAid was established 30 years ago as a nongovernmental organisation (NGO) focusing solely on safe drinking water and improved hygiene and sanitation. Our vision, values and approach were spelled out in the Ethos document by the Founding Director, David Collett, in 1981. They have remained largely unchanged while the organisation has grown and evolved in response to the nature and scale of the challenges faced.

Our current Global Strategy that takes us through to 2015 reflects the context we now work in, and focuses on rights, supply and demand and the challenges of rapid urbanisation, informal settlements, climate change and land ownership. We work to support community action and service providers and governments, to lead and champion Water, Sanitation and Hygiene (WASH) sector development as well as to promote cross sector working.
\end{abstract}

Service delivery remains at the heart of what our partners do. Over the years we have increased our investment in capacity building and advocacy and influencing work. We know our vision of a world where everybody has access to safe water and sanitation will only be achieved if national governments and international donor agencies use their power and resources to accelerate progress towards universal access - and therefore influencing them to do this is now core to our work and that of our partners.

\section{The significance of New Delhi}

The New Delhi Statement was significant for a particular reason (United Nations 1990). While there have been several high-level political commitments to improving water and sanitation over the past 30 years, New Delhi established the principle of equity, i.e. 'Some for All Rather than More for Some' and universalism. In our work, WaterAid promotes equity and inclusion - in terms of resource allocation and in reaching the most excluded, such as older people, disabled people, and people living with HIV/AIDS.

Whilst the Dublin Principles of 1992 (United Nations 1992) placed much greater emphasis on water as an economic good rather than a social good and human right, the Millennium Development Goals (MDGs) of 2000 focused on reducing the proportion of the population without access. This was a good step forward, but even if the MDGs are met, 50 per cent of those in poverty will still not be reached.

The UN declaration of water and sanitation as a right in 2010 has reaffirmed the New Delhi Statement and provides a basis for securing WASH for all. This is not about water for free but about the right of everyone to access water. We believe this is a significant step forward.

\section{Aid flows}

However, there is a declining share of aid flows going to WASH. WaterAid's research on sector investments also shows a lack of clear targeting criteria to the poorest and most off-track countries and communities. In fact, based on studies commissioned to look at World Bank investments, we are in dialogue with them on how equitable access can be achieved. The need for a much stronger focus on equity, and the interrelated nature of the MDGs, were also highlighted at the MDGs review summit in September 2010. 
An integrated approach to environment and health was also a key feature of Delhi. However, the desire to promote individual MDGs may unwittingly work against this objective and create silos of ambition.

WaterAid has long campaigned to focus attention on sanitation. Unfortunately, the 2.4 billion people who lack a safe place to go to the toilet has failed to capture the political imagination, and the environmental problems we faced in London not so very long ago due to lack of adequate sanitation appears to be forgotten. It was only when the Lancet stated that 'diarrhea is now the single biggest killer of children in subSaharan Africa' that the headline appeared to start to resonate more strongly with decisionmakers.

Why is it that the biggest killer does not attract the same response that we have seen to other preventable illnesses such as polio, or the investment made in HIV/AIDS and malaria? Eighty-eight per cent of diarrhoeal deaths are linked to lack of adequate sanitation and safe water and World Health Organization (WHO) figures show that 50 per cent of malnutrition is caused by inadequate water and sanitation. Yet sanitation and water rarely form part of government and donor strategies to improve nutrition, maternal and child health.

WaterAid has recently conducted research on 'What the Health Sector Can and Should Do About Sanitation'. ' A Nepali official we spoke to said, 'People listen to doctors more than they listen to engineers'.

The health sector played a key role in the sanitary revolution in Europe but in developing countries health sector involvement in promoting sanitation is often weak. We all know that the MDGs will only be realised if WASH is integral to education and health and that depends on inter-sectoral collaboration. One of our aims in WaterAid's 2009-15 global strategy is to work across sectors - particularly health and education - in order to mainstream WASH.

\section{Women}

Participatory approaches and the central role of women were key features of both Delhi and Dublin. WaterAid has championed participatory approaches to ensure local ownership of services and the empowerment of women to ensure that governments and service providers take account of the needs and priorities of poor people.

As women and girls carry the burden of water provision for the family - and that of poor hygiene and the sickness that this causes - their central role in decision-making is critical. WaterAid has also been promoting menstrual hygiene management led by women's organisations and the inclusion of other socially excluded and marginalised groups.

I recently visited Ethiopia and was shocked at what I saw in Konso district. Women digging deep into a dry river bed, standing in muddy water 15 feet down and scooping water by the cupful as it seeped out of the sides of the hole; others down deep burrows with only the tops of their heads showing. It took hours for them to fill their jerry cans with murky water which then had to be carried for miles up the mountainsides to their houses.

I also visited Arba Minch University in Ethiopia where WaterAid is supporting an inspirational and innovative programme to help women water engineers to finalise their academic studies. The president of the university shares our belief in the need to train more women to help promote the profile of WASH.

We have learnt much from the work of Kamal Kar and other on Community-led Total Sanitation (CLTS) which further underlines the importance of spending time with communities on behaviour change and generating demand (see Kar, this IDS Bulletin). The importance of community involvement is critical.

The principle of service users informing sector decision-making processes is now relatively well established; however this does not always lead to better services. Unfortunately, at times participation per se is seen as the end, rather than improved services for the poor.

WaterAid aims to support the development and organisational capacity of regional, national and local civil society organisations and networks to engage effectively with governments and donors to advocate for affordable, accessible and appropriate sanitation and water services. 


\section{Appropriate technologies and community management of services}

Delhi promoted the use of lower cost technologies that are appropriate for management at the community level as a means to gain scale. This is very much in line with WaterAid's own thinking but in some cases we think the pendulum has swung too far with government being bypassed or disengaging and communities left unsupported.

Our approach is to work with local government, local civil society organisations and private sector providers to ensure that communities are adequately supported to manage services on a sustainable and equitable basis.

However, as we know, the ability of local governments to effectively support communities is in turn dependent on their relationship with central government and external donor agencies and the systems, finances and human resources required.

As a result, WaterAid works at both community level with local organisations, as well as with national governments. We recognise that the relationship between the Ministry of Finance, the ministries responsible for water and sanitation and international donors is critical to coordinate the multiple sources of finance coming into the sector and to ensure that they are effectively targeted and managed. The Sanitation and Water for All initiative hosted by UNICEF is an example of this.

WaterAid has always focused on sustainable work and recently we have been working with IRG International Water and Sanitation Centre on rural water supply and looking at the functionality of hand pumps. However, we recognise that sustainability is far more than technical capacity as it depends on efficient organisations and infrastructure - the people, the organisations, the systems and of course care for the environment - for example, to ensure latrines do not pollute the water table and water is managed effectively.

\section{Political leadership and accountability for results}

Delhi and Dublin were primarily concerned with technical and financial aspects of managing water and delivering services. However, we know that it is political will, drive and leadership that will secure sanitation and water for all, as we have seen in the education and health sectors.

The sanitation MDG is far off track due to political failure to really tackle the issue. WaterAid's experience shows that those countries that have made the most progress on sanitation are those where strong demand from the ground has been coupled with the championing of water and sanitation issues by political leaders at local, national and international levels.

It is for this reason that we have been a strong supporter of the Sanitation and Water for All (SWA) initiative. ${ }^{2}$ The inaugural High Level Meeting of SWA in April 2010 was the first time that Ministers of Finance from developing countries had come together with ministers of water and external donors to discuss WASH issues, and it marked an important milestone in the development of the sector.

The results of this first meeting were tangible and when in Ghana last year I heard the Minister of Water talk about how this meeting had inspired him and the Finance Minister to increase their attention and investment in WASH. In addition to galvanising political will to address WASH issues, SWA aims to improve the relationship between donor and recipient governments in order to increase the effectiveness of aid to WASH and to allow governments and donors to hold each other accountable for fulfilling political and financial commitments.

Accurate data is an important component of accountability and WaterAid has also been collaborating with UNICEF and WHO over the WHO/UNICEF Joint Monitoring Programme for Water Supply and Sanitation in order to reconcile different sources of data used in East and Southern Africa to improve accountability.

We have produced papers for SACOSAN and AfricaSan to monitor whether donors and governments are fulfilling political and financial commitments. We believe the SWA High Level Meetings will provide a mechanism for consolidating the disparate political and financial commitments within the sector, and improve transparency and accountability.

WaterAid believes that the best way to link community-led approaches and demand with 
political leadership is by combining innovative service delivery and work to support consumer voices and citizen's demand along with targeted advocacy and campaigning at local, national and international levels.

Going forward and post-2015, we believe that the MDGs or similar targets are needed to focus on the poor as we know the sanitation target will not be realised and millions will still be without safe water to drink, or have a decent toilet.

However, we would also want to see the principle of universal access reinforced - which requires

\section{Notes}

1 See www.wateraid.org/documents/ plugin_documents/the_sanitation_problem what_can_and_should_the_health_sector _do_1.pdf (accessed 19 December 2011).

\section{References}

United Nations (1992) The Dublin Statement on Water and Sustainable Development, International Conference on Water and the Environment, Dublin, 31 January 1992, www.ielrc.org/ content/ e9209.pdf (accessed 1 December 2011) increased attention on the marginalised and poorest. Universal coverage does not happen without a focus on those who traditionally miss out.

We also know that where there is a will there is a way, and sanitation and water need high-profile, influential political champions and governments that are committed to improving the lives of the poor and marginalised and a move to greater equity.

In sum we need 'universalisation of the impetus for equality' and 'water and sanitation for all'!

2 See www.sanitationandwaterforall.org/files/ Publications\%20and\%20Resources/SWA_ Fact_Sheet_English.pdf and www.sanitationandwaterforall.org/files/Final HLM_Co-Chairs_Summary_23_April_Eng.pdf

United Nations (1990) New Delhi Statement, Global Consultation on Safe Water and Sanitation, 1990, www.ielrc.org/content/e9005.pdf (accessed 1 December 2011) 